\title{
Some directions for research toward peaceful Arab-Israeli relations: analysis of past events and gaming simulation of the future
}

\author{
JOSEPH D. BEN-DAK ${ }^{1}$ \\ Institute for Intersocietal Relations, Washington, D.C., and Department of Sociology, University of Michigan
}

\section{Introduction}

Since this essay is the last contribution to the symposium, it seems appropriate to reflect on the articulation of means for behavior reversal in the Arab-Israeli conflict. This is predicated upon a prescriptive assessment of the different contributions in the symposium, digesting the array of behaviors realized, and offering certain properties of behaviors that could be part of a new peace system. Some of the reasons for the drought that currently exists in the study of peace (mentioned in our introduction) are then examined in light of this digest, and a research direction that may be more attuned to future event assessment is drawn. Gaming simulation and event data analysis, the two interrelated components of this research strategy, are further explored in terms of their relevant assets and possible compatibility.

In assessing conflict relations between so-

\footnotetext{
'The author would like to record his gratitude to Edward E. Azar, Davis Bobrow, Clinton Fink, William A. Gamson, Johan Galtung, Huang Hua, Herbert Kelman, and Vincent Rock for relevant, thought-provoking discussions. Part of the research backing this essay was also supported by the National Academy of Science (Behavioral Sciences), and the Ford Foundation.
}

cieties, four categories roughly summarize the array of possibilities of both violent and peaceful relations. If the conflict is not governed by normative order and escalates over time, we can label it rancorous conflict behavior (Gamson, 1966) - in the ideal maximum phase all weapons can be used and hostilities cannot be predicted or "managed" by prior behaviors. If a conflict develops to a civil-normative order (i.e., there are rules and "understandings" between parties regarding limits of aggressive behavior), we can label the conflict conventional conflict. If the normative component develops to the point of halting hostilitieseven if defined by the parties as "temporary" - so that the parties tolerate the intervention of a third party that functions by mediating or simply by disassociating the parties, we can label this process conflict settlement. Finally the behavior of all parties can develop or surpass the point of positive relations-i.e., a self-perpetuating and independently reinforcing interaction. Positive relations herein mean (following Galtung, 1967) eliminating fears, anxieties, and exploitation (real and unreal) between the parties, as well as promoting and perpetuating a creative base for more cooperative ties and for exchanges of goods, sentiments, 
resources, knowledge, and beliefs. This is a process of conflict resolution.

Implicit in this typology of relations is hypothesized growth of the normative element in human behavior over time and in essence a reconceptualization of social justice as the end result of conflict resolution behaviors. The focus herein is on testing behavior interactions leading to and from solutions making it possible to study the pros and cons of each solution. Before proceeding with the discussion it should be noted that this approach is markedly different from many currently purporting to solve the conflict by means of assessing what is just as a necessarily known parameter before suggesting concrete moves for the parties. The latter approach is demonstrated in the interesting studies of Galtung (1972), who draws on conflict theory as a yardstick for justice, and of Bassiouni (1970, 1971) who assesses which are real issues and which are only apparent on the basis of a legal discussion.

Such an approach does not discount the part played by the emotions in human affairs. It deals quite directly with the essence of establishing concrete fairness and includes passions, especially those of the underdogs. It does not overcome the notorious constraints of reality-i.e., how to convince the topdog, or for that matter anyone to behave "justly." The international community, and in particular those societies in conflict, are of course seldom well enough ordered to make justice equal, meaningful, or practical for all (Rawls, 1971). This leads to a focus on reason rather than on justice not only in spite of, but probably because of, our emergent collective concern in this symposium as the nature of regularity in Arab-Israeli relations. Reason is not a cause of action, but a regulator of action (Russell, 1954; Howard, 1971). Furthermore it has yet to be proven that a specific plan for a fair solution, while profitable, is a neces- sary condition for initiating a visible conflict settlement or resolution process. Therefore for purposes of this essay and for thinking about peaceful Arab-Israeli relations in general, I assert that an agreement in very general terms by all parties on behaviors that could be implemented immediately is at least as feasible as an agreement on a plan of justice-for-all.

It appears that the research reported in the preceding papers has focused primarily on the movement from one conflict stage to another, and particularly on preventing conventional conflict from deteriorating into rancorous conflict. However in the reported work the potential for rancorous conflict in the Middle East is more evident than the possibility of a continuous settlement; conflict resolution processes are hardly noticeable, even in more speculative parts of the discussions such as those dealing with policy implications.

\section{Prescriptive Research Output}

Let us assume a relatively prescriptive assessment of what is demanded by research reported in the present symposium. The conditions suggested that contribute to a movement away from rancorous conflict are listed below.

(1) Limitation of all immediate Arab military attacks on Israel. Thus even if the Arabs were to engage in a long-range program to eliminate Israel, they would not carry out direct action and therefore could expect less or no Israeli conflict behavior (Wilkenfeld, Lussier, and Tahtinen, 1972). Naturally for conflict resolution to take place all long-range military planning must be minimized (Burrowes and Muzzio, 1972; Blechman, 1972).

(2) Limitation of Israeli retaliatory measures. Israeli retaliatory measures probably diminish formal conflict and limit raids into Israel (Blechman, 1972). However it is also 
likely that Israel must delay all military actions in order for both sides to articulate options for regional cooperation and allow a long-range conflict resolution to develop.

(3) All parties must refrain from any newsworthy military exchange if a prolonged conflict settlement (let alone a resolution) is to be achieved. This conclusion has emerged from the following considerations: (a) Given the high probability that Israel would be victorious in any short-range military confrontation, it is likely that such an exchange would result in the further deterioration of the Arabs' self-concept, particularly considering the UAR's previous humiliation (Siverson, 1972). Thus by avoiding the dichotomy of winner and loser the chances of lessening the differences between parties would be augmented. (b) A military exchange would probably cause a widening of the cleavage that directly exists between Israelis and Arabs, especially since the foreign powers are likely to play a lesser role than they did in 1956 (Azar, 1972). This trend is exemplified in their 1967 behavior. (c) Any confrontation would lead to internal instability, which in most Arab states-and to some extent in Israel toowould be conducive to more foreign conflict behavior (Wilkenfeld, Lussier, and Tahtinen, 1972). (d) Given the Arab expectation of Western constraining (if not punitive) behaviors, it would further reinforce the image of Israel as an extension of the West (Ibrahim, 1972). (e) The formation of negative images in which both the Arabs and Israelis are already engaged would be reinforced (Beit Hallahmi, 1972).

(4) Another necessary condition for settlement is the appointment of an international police force that fulfills the following requisites of composition and authority (Dowty, 1972): (a) the force must be organized in a way that leaves no doubt regarding the situation it is mandated to maintain; (b) it should be composed of contingents from a broad variety of guaranteeing states, excluding the superpowers (see also Ibrahim, 1972) and including states that would be interested in maintaining a peace treaty (Denmark, the Netherlands?) or that could benefit greatly from the reopening of the Suez Canal (Japan, Australia, Norway, Greece?); (c) the force should be equipped and authorized to carry out specified military action; (d) there should be direct bilateral agreements between each guarantor and the guaranteed state or states; and (e) the recall of national contingents should be dependent on the agreement of all local parties.

If we assume a more speculative stance in identifying conditions that could support or comprise a conflict resolution, the following conditions are in order:

(5) Conflict resolution in both intersocietal and intrasocietal contexts is partly conditioned by objectivization and improvement of information availability combined with better communication channels, first and at the very least regarding the image of the other party but also within the parties. This is drawn from the following processes: (a) As the increase in conflict costs becomes known, objectively and subjectively; as behavior preferences are comprehended in their complexity (i.e., as they are modulated or re-ranked); and as salience of public opinion in favor of deescalation increases, Arabs and Israelis are likely to move toward reducing their hostile interactions at least temporarily, and thus to allow for a more thorough peace process to take place (Azar, 1972). (b) Certain components of the real image of the "other" must be communicated in order to de-Satanize the enemy. This implies moving to view Arabs and Israelis as people without extremist coloring (Beit Hallahmi, 1972); comprehending the dynamics of their ideological growth and particularly their national identity (Ibrahim, 1972); and sincere self-preparation for social 
action and interaction with the "other group" (Hofman, 1972). (c) The lack of meaningful communication (i.e., sharing more of the same knowledge about the parties among all parties) heightens the probability that processes leading away from conflict resolution will manifest themselves, and possibly snowball (Hofman, 1972).

(6) An ideology of conflict resolution must involve goals and actions agreeable to Arabs and Israelis, and commit all parties to congruent efforts. Some of the broad categories of such efforts, all of which must have longrange payoff perspectives, are: (a) The ideology must focus on the Palestinian Arab population as a target for social justice. This is simultaneously a challenge for regional inter-Arab politics as well as a central issue in Arab-Israeli relations; thus its solution should be sought on pragmatic as well as ideological grounds (Blechman, 1972; Burrowes and Muzzio, 1972). (b) Part of the ideology of conflict resolution may necessitate the definition of the role and the possible contributions of the major powers, including the United States and the Soviet Union (Ibrahim, 1972). That ideology must suggest, of course, a concerted effort and possibly coordinated roles for the major powers. (c) Increasingly symmetric and direct relations within, between, and among societies (i.e., across political systems and cultures) should be promoted (Hofman, 1972). (d) Thus conflict resolution is to some extent dependent on the ability of Arabs and Israelis to revise the historiography of their relations to fit demands of impartiality and to permit (if not actually encourage) new forms of mutual influence and norms of reciprocity to develop.

\section{Current and Future Research: A Perspective}

Why is it that one finds relatively little research assessing conflict resolution com- pared to the many specific diversified analyses of other behaviors? As many scholars have attempted to articulate (for one example in the context of peace research see Rapoport, 1970, p. 283), decisions about what is relevant in the context of research depends as much on the learned convictions and prior commitments of the scientist as on his scientific dispassionate examination of facts. Thus since so much "trouble" in Arab-Israeli relations ties into the researcher's socialization, historical reflections, study, and sometimes into his concrete personal experiences of intersocietal conflict, it is ony natural that studies of Arab-Israeli relations-not only "conflict" perspectives- would be influenced by a subjective understanding of intersocietal "malfunctioning" (i.e., war). The simple fact that so many thinkers have stopped searching for a definition of peace-that is something more than "the lack of collective, organized violence" (i.e., no war)-makes the choice of perspectives on Arab-Israeli relations limited primarily to the professional "enterprise" of the military.

Thus it is not by chance that the empirical work contained in this symposium tends to equate past and future "conflict" to "relations" between Arabs and Israelis. One may look at this phenomenon as a somewhat more salient extension of the choice of research targets in current work in international relations. Thus the choice of variables by Wilkenfeld, Lussier, and Tahtinen (domestic conflict behavior, the state's prior level of foreign conflict, and foreign conflict directed against the state) is in keeping with the present tradition of believing that systematic knowledge of domestic correlates of international violence is a necessary step toward knowing how to avoid violence. Since the work of Rummel (1963) and Tanter (1964) it has become conventional and "natural" to apply this to other parts of the international system. More striking is Bur- 
rowes and Mussio's enumerative history. While constructed basically with no prior disposition for dealing with conflict events between national communities, it still yields much more in highlighting conflict than in delineating the conditions needed for cooperation between Arabs and Israelis. This is also true for many of the WEIS outputs. In fact event analysis such as Azar's, which focuses on the exchange of hostile signals and their differential conditioning, or Blechman's, which contributes to the understanding of the forms, types of targets, and intensity levels tolerable in Arab-Israeli violence, are quite indicative of trends in mainstream quantitative international relations research.

In the most general sense these belong in a very valuable niche in the accumulation of knowledge about conflicts. Their central assumption is that a great deal of relevant knowledge is buried in the past. A systematic observation and classification of events has already been unfolded to help ascertain (a) which class of conflict Arabs and Israelis are now in; (b) whether that class has most frequently ended in war or any other type of violence; and (c) what sequence of moves might most probably lead to the various outcomes. This is in fact the ideological base for research like that of Singer (1970), who busies himself with reflection on the state of the field, singling this out as the only meaningful approach for the growth of theory in peace research.

I wholeheartedly disagree with notionscertainly not based on the canons of science -of "best" or even "better" in choosing a research direction. However there is danger in recruiting a framework or construct for the vividly tragic past of the Middle East to guide the integration of partlydeveloped theories and isolated bits of data. The danger is due not only to the pessimistic bias inherent in such a framework. Social science is emerging from an epoch in which the quest for punctiform certainty seemed the optimal approach to knowledge (Campbell, 1966, p. 83). What we seem to agree on, still more in principle than in practicing the search for knowledge, is that (a) insofar as any certainty - a kind of "proof" of validity of any given section is achieved-it is because a prior identification of the whole has been "stipulated"; and (b) "rather than the identification of the whole being achieved through the firm establishment of particles the reverse is the case, the complex being more certainly known than the elements, and neither of course being known incorrigibly"' (Campbell, 1966).

Thus if it is peace (i.e., conflict settlement, conflict resolution) that we are investigating, a profitable research direction could be to use a methodology of creating new "wholes", and once such wholes are stipulated of studying their particles. Wholes may be newer and less conflict-oriented classes of relations between Arabs and Israelis. In looking for their particles, the body of knowledge accumulated through the study of past behaviors, interrelating events series, and assessing the sequence of moves leading to outcomes (realized and unrealized) would be very advantageous.

There are a few methodological means by which one can realize this type of linkage between past and foreseeable future, between overmeaningful war and meaningful peace. The remainder of this essay will discuss the merits of one-namely a wedding of familiar event data analysis and gaming simulation.

As a few researchers have demonstrated in this symposium, event analysis is based on manipulation of units of inter-nation behavior which contain these components: an actor, a target, a date, an activity, and an issue-area. The actor and target are nation states, national communities, or organizations. The date is the calendar day, month, and year on which the action took place. The activity is a verbal or physical action 
from actor toward a target. The issue-area is a residual category including the arena or matter about which the actor and target interact.

Gaming simulation can be explained as follows. We define gaming as structured interactions between players of roles and simulation as information manipulation, normally as in-machine computer operations, on models or sets of linked models that extract meaningful relations from the real world. Hence gaming simulation refers to research in which gaming is merged with information manipulaiion (usually computer simulations) into one vehicle (cf. Ray and Duke, 1968, p. 149). Some of the formal properties of the two methodologies are analytically similar and, as we will try to demonstrate, highly complementary. The similarities are between the operational definition of actor and target vis-a-vis the simulated roles, activity and the simulated interaction, and the issue-area and the simulation combination of goals and resources. In our treatment of simulation here we will not enter the more general discussion of its pros and cons (see for example Inbar and Stoll, 1972; Coplin, 1968; Ben-Dak, 1972a).

\section{Gaming Simulation in the Study of \\ Arab-Israeli Relations}

Pertinent work has been done in the area of "crisis gaming." Several researchers and institutions, particularly in Great Britain, have produced simulation models that are comparable to conventional research, such as that represented in this volume, with regard to information input (see Banks, 1968; Newnham, 1968). The typical "crisis gamers" concentrate almost exclusively on gaming and use little or no simulation.

The kind of outcome they offer is illustrated best by their own review:

Conex I: A pacific outcome. The Eshkol player, from the first resolutely opposed the suggestion that Israel should develop nuclear weapons; he carried his team members with him and, in spite of a good deal of hostile wrangling within the Arab team, the game ended with a non-proliferation conference.

Conex II: The game ended with an Egyptian attack on Israel, to some extent coordinated with Jordan. The players (mostly United States Air Force officers) took a much cooler view of nuclear weapons and more or less dismissed them as too big, and too dangerous because of fallout on friendly countries. After that, the game gradually became more aggressive on conventional military lines [Banks et al., 1968, p. 8].

In such outcomes one finds little if any peace insight into peace-oriented directions for research on the intersocietal situation. The first example denotes concentration and concern with the nuclear military potential in a manner hardly relevant to the referent system, and is too much influenced by the individual participants (e.g., the Eshkol player). The second illustration denotes no new information (i.e., not known from conventional conflict research) and lacks validity (e.g., lack of corresponding intelligence function in the coordination of the policy decisions).

The kind of data derived from this type of simulation to buttress further research is (1) pregame attitude questionnaires (pertinent to nuclear proliferation in the conflict situation); (2) tension ratings (an index of international "tension" or hostility between states); (3) simulator's observation of causes of tension; and (4) conceptual frameworks the players use to try to achieve their foreign policy goals as they are understood to exist in the referent system.

Again it is precisely because these outcomes and data are premised with a "real world" over-realism that their outcomes are somewhat inconsequential: elements of intersocietal life that have little or nothing to do with war are hardly noticeable. The data extracted could be gained very well without the use of a simulated environment or a game atmosphere. Attitudes on nuclear pro- 
liferation for example can be much better assessed by personally interviewing retired decision-makers (e.g., Jules Moch of France), whose insight into and knowledge of the weapon's potential and inspection chances are superior to the experience of a game. Clearly differentiation between the current nature of the conflict system and the realm of the possible has not been taken too seriously. One of the greatest advantages of simulating the Arab-Israeli relationship is that the rules do not forbid the evolution and realization of roles, resources, interactions, sequence of events, etc., except those that would be impossible in the real situation.

From the above review of methodologies, simulation and non-simulation, it appears that two requirements are paramount if one is to seriously engage in gaming simulation as a peace research tool. First an acceptable level of referent system validity in the simulation for particular problems of research must be achieved, and second the means by which the simulation can enable the researcher as well as participants to articulate resources and patterns relevant in particular to peace propensities in the intersocietal system must be suggested.

Have these two requirements been realized in any other type of simulation gaming? Steinbruner (1970) developed a Middle Eastern game played by a group of foreign policy specialists. The scenario was designed to force teams of players to make a careful assessment of the intentions of their adversaries before weighing alternative courses of action (see Bonham and Shapiro, 1972). Game materials were sufficiently plausible and rich to ensure the involvement of players who had dealt with Arab-Israeli relations of more "conventional" realism. Consider the setting of the game: ArabIsraeli relations in June 1970 (first decision period) and in January 1971 (second decision period).
The first period scenario began with the presentation by the French of a proposal for a Middle East settlement involving Israeli withdrawal to the borders of May 1967, a demilitarization of border areas, and an international force patrolling border areas. All states of the area in unspecified manner were to be guaranteed the right to exist and passage through the Straits of Tiran. There was no mention of Suez.

In the first period the teams were asked to recommend whether or not the French proposal should be accepted as a basis for formal negotiations involving the four powers (U.S., U.S.S.R., Britain, France) and the states of the area.

After the teams made their recommendation they were told that the "President" rejected the proposal as a basis for negotiations on the grounds that since it was completely unacceptable to Israel, it did not offer a serious chance of improving the situation.

In the second decision period the teams were given evidence that the Soviet and the Syrian regimes had collaborated to introduce tactical nuclear weapons systems into Syria. The teams were given three alternative courses of action based on the assumption that this was true: (1) an air strike against the Syrian bases where the weapons were deployed, (2) military aid to Israel involving "dual-key" control of nuclear weapons and buildup of the U.S. Sixth Fleet, (3) a negotiated settlement along the lines of the French proposal from the first period with a temporary deployment of U.S. forces to guarantee Israeli borders (and, upon withdrawing, to secure similar withdrawal of Soviet weapons). The teams were instructed to choose among these three options and to state the rationale for their choice [Steinbruner, 1970, pp. 41-42].

Such gaming payoffs were, among others:

(a) Dealing with uncertainties in the scenario and in real-life decision-making involving the intentions of the Soviet Union, at least to the extent of situations that have yet to be realized. This yielded a series of specific hypotheses regarding the expected behaviors of the USSR and the rationale behind them.

(b) Through a special collection of information from the players, decision-makers' cognitive structure has been established in the simulation as a map of causal linkages 
among three types of concepts. "Affective" concepts refer to the policy objectives or interests of the actors in the conflict; "cognitive" concepts denote beliefs about actions that occur in the conflict; and "conative" concepts indicate possible alternatives from which the decision-maker selects policy recommendations. Real data on each of these types is scarce, and it is almost impossible to secure a working notion of the interrelationships. An event or a series of events can be related to a decision-maker's policy alternatives and policy objectives thrugh such mapping. This work was the basis for further simulation processing and resulted in different explanations of the Jordanian crisis of 1970 .

(c) The game's consequences of the Jordanian regime's fall (replacement by a radical regime, further polarization in the area leading to a high propensity for war) were accessible to close analysis of the sort that one would want, enabling the researchers to comprehend the relation between varying cognitive maps and realized strategies.

A scenario of September 15, 1973, was devised by a group led by Shure (Shure et al., 1968, 1969). Palestinian guerrilla activities and a breaking-down of a working arrangement under which Israeli cargoes had been moving through the Suez Canal are the center of the simulated events. Different groups of participants-college undergraduates, graduate students in social psychology, "expert" players (from RAND, UCLA faculty), and Department of State officials-participated in different runs. Video tape and resulting protocols provided data for records of performance that are comparable across levels of expertise and sophistication. Analyses in this case can:

(a) Identify the differences in team behavior and generally relate these to characteristic differences among the groups along such dimensions as the mode of problem definition, methods of problem attack, uti- lization of information, degree of contingency planning, extent of perceived constraints, sensitivity to adversary positions, concern for the forms, and expectations of international protocol, etc. These differences should be illuminating not only in a substantive sense, but also for developing a frame of reference for choosing the best game participants for this confrontation.

(b) Answer questions such as "to what extent can the USSR and the United States be expected to collaborate in a local crisis in which they have backed the opposite side?" (the USSR appeared more willing, in a number of ways, to become directly involved in the Middle East); " to what extent and in what ways do Egypt and Israel desire to involve or avoid the superpowers in a Middle East confrontation?"; and "to what extent do crises provide opportunities to attempt solutions to underlying problems in the area?" (Shure, 1969, p. 32).

(c) Facilitate the study of in-process bargaining phenomena. Even in simulated ArabIsraeli relations however, certain phenomena cannot easily be studied because they occur rarely, or follow unique patterns of antecedent events, or require more extensive subjective analysis than can easily be obtained during the experiment (cf. Terebinski et al., 1968). An example of such a situation is an Arab state X's sudden shift to aggressive moves in a condition that had been stable and characterized by cooperation, and where no outside triggering event could be detected (cf. Blanchard, 1968). Control and standardization of such a situation is given by the simulation records of antecedent events. The data are screened through situation-playing, using a questionnaire form that amplifies motivations and perceptions related to preferred choices. This method has been named SCENQUEST (Terebinski et al., 1968).

From the above review, it should be obvi- 
ous that gaming simulation has become relatively attractive in supplying validity for hypothesis testing and theory generation in Arab-Israeli relations, a situation that is haunted by missing information and complexity. Furthermore many of the examples can be regarded as "hypothetical," if not "futuristic," event data analysis. What we have found still lacking is new knowledge about conflict settlement and resolution.

That gaming simulation can produce more pertinent peace data has been suggested in general work on future experiments (see for instance, Ben-Dak, 1970c; Clemens, 1970; Smoker, 1972) and in a series of reports on a peace gaming simulation of ArabIsraeli relations (Ben-Dak, 1969, 1970b, 1972). In this type of gaming all efforts are designed to allow for a different "whole" to emerge, provided it is not entirely impossible by the simulator and participants' standards of realism. Some of the techniques used here, in addition to the more usual gaming construction mentioned above, are:

(a) Each game consists of two runs in which each player assumes different, preferably opposing roles whose meeting points he is to evaluate upon finishing the game.

(b) A group of peace specialists (an agency not existing in reality) simulates an abundance of "how to" knowledge derived from peace research and science.

(c) Participants do research before and after the gaming simulation with real world data, preparing for the game and for evaluating gaming results in terms of contribution to conflict settlement or resolution.

(d) There is an inducement for innovative alliances between and among all possible parties and the use of resources (domestic and foreign) in an unconventional manner.

(e) Student activists were used, in some runs, as decision-makers who even though they had to use conventional means-given the game's rules-still performed differently (though realistically) in processing conflict resolution.

Some of the questions such games are able to answer over about a dozen runs are:

(a) Under which conditions would Chinese involvement with Arab-Israeli relations support a process of conflict resolution, and which resources could the Chinese contribute? A notion of a very positive Chinese role in the conflict emerged, especially given their role vis-a-vis the Palestinians. Chinese expertise could be relevant for communal planning, and could serve as an intermediary channel for Israeli-Palestinian cooperation. This of course needs much more study, but in itself is a sharp departure from conventional research on China's role in the Middle East (see Ben-Dak, 1972a, 1972b; cf. Medzini, 1971; Cooper, 1969).

(b) Under which conditions could disarmament take place in the region? The games indicated futility for virtually all processes aimed at arms control and disarmament as long as conflict resolution is not attainable. Game events are in this case in sharp disagreement with suggested strategies leading to effective disarmament. Both types of conditions can be studied profitably if they are interrelated.

(c) The game depicted certain states as able to promote peace actions, similar to Dowty's assertions (1972) regarding the international peace force.

(d) Would the subjective definition of social justice for the Palestinians remain continuously one that can be achieved only by enormous structural changes in Israel? The games suggested the growth of a new kind of pluralistic society that disregards borders, once an independent Palestinian state is established. Thus issues of social justice would have a different flavor and direction.

In relating gaming simulations to event data analysis of the sort demonstrated in this symposium by Azar; Blechman; Burrowes 
and Muzzio; and Wilkenfeld, Lussier, and Tahtinen it appears that knowledge on ArabIsraeli relations can be enriched in several ways:

More hypothetical situations could be subjected to dynamic analysis. Thus consequences of certain behaviors and future interactions and strategies can be elucidated. For example the positive and negative peace consequences of policy implications of limiting military behaviors (limiting immediate Arab attacks and/or limiting Israeli retaliation measures and/or refraining from all military moves) can be subjected to meaningful propositions.

Different levels of processes and research fruits could be interrelated. Thus conclusions relative to information availability and communication channels can be tested for implementation. Another example is the possibility of relating background data of peoples' aspirations and attitudes (e.g., derived from Ibrahim, 1972; Hofman, 1972) to simulated events through role-background or rules about possible interaction between parties.

Gaming simulation can deal with situations of missing data by reproducing conditions similar to those under which such data emerged or could emerge. This could be equally true for the USSR in the 1970s and the historical interaction between the Zionists, the Arabs, and the British, and the Inter-Allied Peace Commission of 1919 (see Vereté, 1967).

A new, innovative perspective could help redefine resources, roles, goals, and classes of events. One example of this is the role of the People's Republic of China. Another would be a concept for the Palestinian guerrilla activities in a conflict resolution process.

\section{Improving Event Data Analysis}

One of the obvious disadvantages of event data analysis is that the data is separated from its immediate, specific, and detailed context. A typical coding will yield a limited amount of information: a score measuring event intensity (e.g., in Azar's data bank, COPDAB, one of 13 points along a conflictcooperation dimension); activity (normally a one-word alphabetic descriptor of the actions the nation is engaged in); and issuearea (a complementary category that elaborates the information already coded on the event). The limited space alloted to the coding of activity and issue-area may limit its usefulness (Burgess et al., 1972). When dealing with events in the aggregate, one realizes that they originate from noncommon contexts, but the assumption must be of course that the contexts indicate a random distribution of significant properties. Contrarily in gaming the context is fully defined and the researcher has control of most of the eventproducing environment. If matched in interrelated research, this prospect of contextfree event data and simulated contexts may have far-reaching consequences in assessing causal relations between events, any contextual variables, and their combination. Establishing causality between simulated context, i.e. relevant and irrelevant conditions, and real world events is identical to experimental work (Galtung, 1967a; Wold, 1956).

Events can be said to have been caused by a simulation gaming context if the context is valid (the simulated variables are true and accurate representations of those aspects of the real situation that they are intended to simulate); if the game is comprehensive (all the important aspects of the real situation are included in sufficient detail); and if it is verisimilar (the game gives the players the feeling of being in the real situation) (Inbar and Stoll, 1972, p. 281); and if the following four conditions are fulfilled.

(a) There is no appreciable time lag between changes on the independent and the dependent sides, i.e. there is immediacy of the effect; 
(b) There is high precision prediction of the value of the dependent variable from the value of the independent variable (or groups thereof), i.e. determinism;

(c) For higher values of the independent variable(s), there will be at least no lower values on the dependent variable, i.e. monotoneity;

(d) The relations between the independent and dependent variable(s) hold regardless of the state of the rest of the world, i.e. all other variables are irrelevant conditions (Galtung, 1967b).

For the peace policy aspect of our work, one needs to add a fifth condition:

(e) The independent variable is manipulable, i.e. a simulator or a player can make a coherent (interpretable in terms of policy in the real world) change in the value of the independent variable so as to start the machinery (Galtung, 1967a).

These are not all the conditions for inferring cause and effect, nor is the model they imply (cf. Galtung, 1967b) the only possible one. However these seem to include the most reasonable relationships between the simulation realm and the events. Ideally a researcher should be able to smoothly move from contextual variables in the referent system (given a well-defined problem) to simulated ones. Somewhat more problematic is the relationship between simulated events and real world ones. The difference is partly due to the limit on the number of decisions that can be made in the gaming. The gaming part, which provides human insight and imagination, also has its cost. However the simulation part should help approximate output to real world data.

Since the applications of the combined effort have been spelled out in the previous sections, a few criteria for data collection are in order so as to provide quality control of data banks necessary to meet the challenge of the causal analysis suggested above. These are suggestions that transcend the immediate focus of the "combined" effort.

\section{VARIABLE TIME AND ACTOR COLLECTION PROCESS}

Data banks differ according to their use of time and actors covered. Azar's COPDAB data base is longitudinal, including almost 100,000 events since 1918. These events were either initiated or received by some 15 "large and major" actors, and 25 Middle Eastern, North African, and small northwest Asian actors. Thus any actions which were either received or initiated by Egypt, Syria, Israel, Iraq, Lebanon or Jordan can be found at COPDAB. Compared to this, WEIS focuses on the limited period of 1966-69, and apparently has only a portion of 23,000 events for the Middle East actors, since all world actors are included. Mansour's data is post-World War II, and the actors are all Arabs. (Thus Israel would appear as a target only.) From our standpoint the longer the period covered and the more interactions covered between the Middle East and other actors, the better the data base. Coverage of interactions is not only measured in sheer number, but also in inclusion of all institutional spheres. Interactions that transcend a narrow definition of political events is necessary. Thus cultural or symbolic transactions, or events pertinent to psychological give and take (i.e., freedom from fear) need operationalization and inclusion.

\section{REGIONAL FOCUS}

Data banks that are regional in scope seem to be more promising than globallyoriented ones (cf. Robert Burrowes' MECCA vis-a-vis the WEIS project). This is true not only because less data is allowed to be lost, but also because the regional perspective enables the researcher to gain substantive knowledge necessary to assess the relation between concepts and their mea- 
surement (Burgess et al., 1972). Much work is needed in studying relatively unique ArabIsraeli events. For example the concept of "imaginary event"-i.e., an event that though reported by a source did not happen -needs to be elaborated. The Middle East seems to have more than its share of such events.

\section{SOURCE COVERAGE}

Azar; Burrowes and Muzzio; Wilkenfeld, Lussier, and Tahtinen; and Blechman addressed themselves to the question of source coverage. While McClelland's WEIS uses one or two sources (the New York Times and occasionally the London Times), the Mansour data bank (University of Wisconsin) cannot trace events to sourcesalthough it uses many. There should hardly be any doubt that the utilization of a single source has no place in Arab-Israeli relations. Poor data, political myopia, and cultural biases will be obvious consequences.

A lugubrious fact is that few have used the most reliable printed collection of events in Arab-Israeli relations, the Middle East Record. Even those who have a multiple source orientation have not coded from it (Azar, Burrowes and Muzzio). As suggested in the introduction to this symposium, this should change soon for both Arab-produced and Israeli-produced data.

Burrowes and Spector (1971) imply that a minimal prerequisite for events data projects is a thorough comparison of the strengths, weaknesses, and yield patterns of their resources. This becomes a firstorder task as the type of combined efforts we advocate begin to materialize.

\section{AGGREGATION AND SCALING OF EVENTS} DATA

Among the more promising properties of Azar's data is its versatility. By this I mean the ability of a researcher to regroup, rescale or recategorize the data in a manner which the operationalization of one's variables demand. Although every event in COPDAB is scaled on Azar's 13-point scale, ranging from very cooperative (scale value 1) to very conflictful (scale value 13), one can use other scaling units and categorization schema because the coded events retain the original components of the originally reported event in a very succinct, yet sufficiently simple manner. The data are not categorized into a set of categories (such as McClelland has done with WEIS). One can use his own categories rather than be forced to use the categories of the data maker. This is one very important feature of data banking which very few large-scale data bases have. Thus aggregation, disaggregation, and recategorization are very useful properties of the data, and allow one to test competing hypotheses with one form of data organization, or one hypothesis with different types of data aggregation for the purpose of studying the effect of data organization and data rankings on the substantive issues of the conflict and its resolution.

\section{Conclusion}

In the introduction to the symposium, we noted a few trends that seemed promising for the study of Arab-Israeli relations and the identification of new patterns in particular: a systematization of data collection and data making; the legitimization of nontraditional opinions and better dissemination of all parties' views; and the ever-widening scope for the understanding of Arab-Israeli relations. This essay attempted to elaborate on these in terms of behavior data. The weaknesses currently found in event data analysis of the Middle East need to be dealt with in order to comprehend past behaviors. Other quantifiable properties' background variables of the Middle East may be in need of similar improvement or supplementation, e.g. cross-national data, specific conflict 
data, or international organization data.

However instead of drawing on these properties of the system as the context providing variables, the position advocated here was to interrelate simulated contexts and real world event data. Such research will complement study directions documented in the symposium in tackling aspects of future behavior, and not only past behaviors. Furthermore it will possibly test for antecedents and consequences of a conflict resolution.

It is with much loving care that different instruments and better data must be prepared, if we are to research realistic contexts of future Arab and Israeli peace behaviors.

\section{REFERENCES}

Azar, Edward E. The analysis of international events, Peace Research Reviews, 1970, 4 (Nov.), 1-113.

The conflict escalation-reduction cycle: a statistical assessment of interaction shifts. Studies of Conflict and Peace, University of North Carolina, Chapel Hill, 1971a.

. Conflict and Peace Data Bank: A Code-

book. Chapel Hill, N.C.: University of North Carolina, Studies of Conflict and Peace, 1971b. Conflict escalation and conflict reduction in an international crisis: Suez, 1956, Journal of Conflict Resolution, 1972, 6 (2, June), 183201.

and Joseph D. Ben-Dak (eds.). International Interaction: Theory and Practice of Events Analysis. New York: Gordon and Breach, 1972 (forthcoming).

Banks, M.H., A.J. Groom, and A.N. Oppenheim. International crisis gaming: the CONEX experience. In Proceedings of the Second International Peace Research Association (IPRA) General Conference. Netherlands: Vangorcum, 1968.

Bassiouni, M. Cherif, and Eugene M. Fisher. The Arab-Israeli conflict-real and apparent issues: an insight into its future from the lessons of the past, St. John's Law Review, 1970, 44 (Jan.).

"Self-determination" and the Palestinians. In Proceedings of the American Society of International Law. Lancaster, $\mathrm{Pa}$.: Lancaster Press, 1971.
Beit-Hallahmi, Benjamin. Some psychosocial and cultural factors in the Arab-Israeli conflict: a review of the literature, Journal of Conflict Resolution, 1972, 6 (2, June), 269-80.

Ben-Dak, Joseph D. A social simulation strategy for researching Arab-Israeli relations. In Proceedings of Ninth Symposium of the National Gaming Council. Washington, D.C.: Environmetrics, 1970a.

. Time for reorientation: a review of recent research on the Arab-Israeli conflict, Journal of Conflict Resolution, 1970b, 14 (1, March), 101-12.

A social simulation for studying peace in an intersocietal conflict: researching China's role in Arab-Israeli relations. Paper presented to the Fourth International Peace Research Association (IPRA) General Conference, (October), 1971, Bled, Yugoslavia.

(ed.). Simulation of Intersocietal Relations. New York: Gordon and Breach, 1972a (in press).

___. China and peace in the Middle East, Middle East Information Series, 1972b, 18 (April), 30-35.

Blanchard, W.H. Notes on a theory of American character and its implications for bargaining and negotiating. Los Angeles, Calif: System Development Corporation document SP-3200 (draft), June 10, 1968.

Blechman, Barry M. The impact of Israel's reprisals on behavior of the bordering Arab nations directed at Israel, Journal of Conflict Resolution, 1972, 6 (2, June), 155-81.

Bonham, G. Matthew, and Michael J. Shapiro. Simulating foreign policy decision-making: an application to the Middle East. In Joseph D. Ben-Dak (ed.), Simulation of Intersocietal Relations. New York: Gordon and Breach, 1972 (in press).

Burgess, Philip M., Raymond W. Lawton, and Thomas P. Kridler. Indicators of international behavior: an overview and re-examination of micro-macro designs. Paper presented to the Annual Convention of the International Studies Association, March 1972, Dallas, Texas.

Burrowes, Robert, and Douglas Muzzio. The road to the Six Day War: aspects of an enumerative history of four Arab states and Israel, 19651967, Journal of Conflict Resolution, 1972, 6 (2, June), 211-26.

and Bert Spector. Sources of Middle East international event data, Middle East Studies Association Bulletin, 1971, 5, (2, May 1), 54-71. 
and Bert Spector. The strength and direction of relationships between domestic and external conflict and cooperation: Syria, 19611967. In Jonathan Wilkenfeld (ed.), Conflict Behavior and Linkage Politics. New York: David McKay, 1972 (forthcoming).

Campbell, Donald T., John R. Raser, and Richard Chadwick. Gaming and simulation for developing theory relevant to international relations, General Systems, 1970, 15.

Clemens, Walter R. A bibliographical note on recent literature on the Middle East, War/Peace Report, 1970, (June/July).

Cooper, John F. Chinese objectives in the Middle East, China Report, 1969, (Jan.).

Coplin, William D. Simulation in the Study of Politics. Chicago, Ill.: Markham Press, 1968.

Dowty, Alan. The application of international guarantees to the Egypt-Israel conflict, Journal of Conflict Resolution, 1972, 6 (2, June), 253-67.

Galtung, Johan. Diachronic correlation, process analysis and causal analysis. International Peace Research Institute, Oslo, Norway, 1967a. Theory and Methods of Social Research. Oslo, Norway: Oslo University Press, 1967b. . Theories of peace. International Peace Research Institute, Oslo, Norway, $1967 \mathrm{c}$. . The Middle East and the theory of conflict, Journal of Peace Research, 1972, 9 (1), 173-206.

Gamson, William. Rancorous conflict in community, American Sociological Review, 1966, (Feb.), 71-81.

Howard, Nigel. Paradoxes of Rationality: Theory of Metagames and Political Behavior. Cambridge, Mass.: MIT Press, 1971.

Hofman, John E. Readiness for social relations between Arabs and Jews in Israel, Journal of Conflict Resolution, 1972, 6 (2, June), 241-51.

Ibrahim, Saad E. M. Arab images of the United States and the Soviet Union before and after the June War of 1967, Journal of Conflict Resolution, 1972, 6 (2, June), 227-40.

Inbar, Michael, and Clarice S. Stoll (eds.). Simulation and Gaming in Social Science. New York: Free Press, 1972.

McClelland, Charles A. International Interaction Analysis: Basic Research and Some Practical Applications. Technical Report \#2, World Event/Interaction Survey (WEIS). Los Angeles: University of Southern California, November, 1968.

Medzini, Miron. China and Palestine: a developing relationship, New Middle East, 1971, (May).
Newnham, J.D. Arab-Israeli relations: a pilot study of international attitudes, International Problems, 1967, (5), 81-90.

Rapoport, Anatol. Can peace research be applied?, Journal of Conflict Resolution, 1970, 14, (2, June), 277-286.

Rawls, John. A Theory of Justice. Cambridge, Mass.: Harvard University Press, 1971.

Ray, Paul H., and Richard D. Duke. The environment of decision-makers in urban gaming simulations. In William Coplin (ed.), Simulation in the Study of Politics. Chicago, Ill.: Markham Press, 1968.

Rummel, R.J. The dimensionality of nations project. In Richard Merritt and Stein Rokkan (eds.), Comparing Nations. New Haven, Conn.: Yale University Press, 1965.

Dimensions of conflict behavior within and between nations, General Systems: Yearbook of the Society for General Systems Research, 1963, 8, 1-50.

Russell, Bertrand. Human Society in Ethics and Politics. London: Allen and Unwin, 1954.

Shure, Gerald H., et al. Participant materials for "Simulation of a Middle East Crisis 1973, Version I" for faculty participants. System Development Corporation document SP-3249/000/01 (draft), Oct. 17, 1968.

and R.J. Meeker. On-line computer studies of bargaining and negotiation behavior: final report for contract DAH 15-67-C-0277, System Development Corporation, 1970 (September).

Singer, J. David. Data-making in international relations, Behavioral Science, 1965, 10, (1, Jan.), 68-80.

. Editor's introduction. In Quantitative International Politics: Insights and Evidence. New York: Free Press, 1967.

The outcome of arms races: a policy problem and a research approach. In Proceedings of the International Peace Research Association (IPRA) Third General Conference. Netherlands: Van Gorcum, 1970.

Siverson, Randolph M. The evaluation of self, allies, and enemies in the 1956 Suez Crisis, Journal of Conflict Resolution, 1972, 6 (2, June), 203-10.

Smoker, Paul. Anarchism, peace and control: some ideas for future experiments. Paper presented to the Fourth International Peace Research Association (IPRA) General Conference, 1971, (October), Bled, Yugoslavia.

Steinbruner, John D. Some effects of decision procedures on policy outcomes. MIT Center 
for International Studies, 1970, (February), C/70-9.

Tanter, Raymond. Dimensions of conflict behavior within and between nations 1958-1960. Doctoral dissertation, Indiana University, 1964.

Terebinski, S.J., et al. SCENQUEST: a scenario questionnaire technique applied to the study of coalition formation. System Development Corporation document SP-3441, 1968 (Feb.).

Vereté, Mayir. Zionist-Arab-British relations and the Inter-Allied Peace Commission, 1919, ZION, 1967, 32, (1-2).

Wilkenfeld, Jonathan, Virginia Lee Lussier, and Dale Tahtinen. Conflict interactions in the Middle East, 1949-1967, Journal of Conflict Resolution, 1972, 6 (2, June), 135-54.

Wold, Herman. Causal inference from observation data, a review of ends and means, Journal of the Royal Statistical Society, 1956, 119 (Series A). 